\title{
Tau protein concentrations in cerebrospinal fluid of patients with dementia of the Alzheimer type
}

\author{
Rita E Tato, Ana Frank, Angel Hernanz
}

\begin{abstract}
Tau protein concentrations were measured in the CSF of 23 patients with dementia of the Alzheimer type (DAT), 36 patients with multi-infarct dementia (MID), and 23 control subjects. Tau protein concentrations were significantly higher in patients with DAT than in controls $(P<0.001)$ and patients with MID $(P<0.001)$. A significantly positive correlation between CSF tau protein and glucose concentrations $(r=0 \cdot 79, \quad P<$ $0 \cdot 001)$ and evolution of disease $(r=0.47$, $P<0.05)$, and a negative correlation with Folstein's mental state examination test $(r=-0.73, \quad P<0.001)$ were found in patients with DAT.
\end{abstract}

$(\Im$ Neurol Neurosurg Psychiatry 1995;59:280-283)

Keywords: cerebrospinal fluid; tau protein; MSE test; Alzheimer's disease; multi-infarct dementia

Dementia of Alzheimer type (DAT) is a brain disorder characterised by a progressive dementia that occurs in middle or late life. The neuropathological changes associated with DAT include the presence of neurofibrillary tangles, neuritic plaques, and granulovacuolar degeneration..$^{12}$ Neurofibrillary tangles are neuronal inclusions that consist of dense accumulation of pathological paired helical filaments, of which the main component is a modified form of the microtubule associated tau protein. ${ }^{3}$ Although none of these changes are unique to Alzheimer's disease, their quantitative correlation with clinical dementia is well documented. ${ }^{4-6}$ Tau protein is known to be important for maintaining the stability of axonal microtubules involved in the mediation of fast axonal transport of synaptic constituents. In DAT, tau protein becomes abnormally phosphorylated, leading to a decreased stability of the microtubular network with concomitant impairment of the anterograde axonal transport system and to an increase in the amount of tau protein per neuron. ${ }^{37}$

Because tau protein is normally an intracellular compound, the amount found in CSF is low. Quantitative determination of insoluble tau protein has been carried out postmortem, in both the grey and white matter of brain regions. ${ }^{38}$ The development of specific monoclonal antibodies with high activity for tau protein has recently led to a commercial enzyme linked immunosorbent assay (ELISA) test for detection of tau protein in brain tissue. ${ }^{9-12}$ To our knowledge, however, there is only one report published about the quantitative detection of tau protein in $\mathrm{CSF}^{13}$ and the results obtained need to be confirmed by other studies.

There is evidence about peptidergic abnormality in DAT such as the loss of cortical somatostatin, which has been correlated with a decrease in CSF somatostatin. ${ }^{91415}$ Reports on other neuropeptides such as substance $P$ or neuropeptide $\mathrm{Y}$ are contradictory ${ }^{15-17}$ and a possible relation between these neuropeptides and tau protein in CSF has not yet been described.

The aim of this study was to measure tau protein in the CSF of patients with DAT Alzheimer type and patients with MID to clarify if its concentration was different in the two dementia types and age matched controls. We also aimed to establish whether its concentration in CSF was related to that of neuropeptide $\mathrm{Y}$, somatostatin, and substance $P$, as well as with the physiological and biological state of patients with DAT.

\section{Materials and methods}

SUBJECTS

Patients with dementia and controls were in good general medical health and were from the neurology unit at $\mathrm{La} \mathrm{Paz}$ Hospital. The control group comprised 23 subjects (13 men and 10 women with a mean (SD) age of 67 (11) years), in whom a lumbar puncture was performed for persistent cephalalgia to rule out a meningeal syndrome. None of them had any abnormality on physical examination and routine laboratory blood tests, and CSF was normal in biochemical, microbiological, and cytological analysis. Patients in the DAT group ( $n=23$, eight men and 15 women with a mean (SD) age of 70 (7) years) met the DSM-III-R and NINCDS-ADRA criteria for DAT. All patients showed brain atrophy and no sign of cerebral infarction or leukoaraiosis as determined by CT or MRI. Patients in the MID group ( $\mathrm{n}=36,19$ men and 17 women with a mean (SD) age of 70 (8) years) fulfilled the DSM-III-R criteria for dementia and all had undergone careful neuropsychological (Hachinski ischaemic score and Rosen score) and radiological evaluations (CT and MRI), which were in agreement with the clinical diagnosis of MID. Duration of disease was 41 (SD 27) months and 40 (SD 32) months in patients with DAT and those with MID respectively. Cognitive function was examined 
with Folstein's mental state examination (MSE) test and the Blessed score. Patients were mildly to moderately demented as measured by DSM III criteria (modified by Jorm and Henderson) and MSE. None of the patients were taking psychotropic (neuroleptics or antidepressants) or immunosuppressive medication and no symptoms or signs of major depressive disorders were found. The table shows the patients' characteristics.

\section{ANALYTICAL METHODS}

A sample of CSF was removed from the lumbar subarachnoid space between 930 and $1030 \mathrm{am}$ after an overnight fast and collected in plastic tubes containing EDTA (Merck) and aprotinin (Boehringer Mannheim). Cells were immediately removed by centrifugation and CSF samples were frozen at $-40^{\circ} \mathrm{C}$ until analysis. At the same time as lumbar puncture blood samples were collected to obtain serum and the serum was stored at $-40^{\circ} \mathrm{C}$ until assay.

Glucose and total protein concentrations in CSF were determined with standard methods using a Hitachi 704 autoanalyser (Boehringer Mannheim). Tau protein was measured in CSF with a commercial tau specific sandwich ELISA (Innogenetics). The sensitivity was $<10 \mathrm{pg} / \mathrm{ml}$ and intra-assay variation $<8 \%$. The ELISA measures total tau and does not distinguish between phosphorylated and unphosphorylated tau protein. Neuropeptide like immunoreactivities were measured by commercial radioimmunoassays for the quantitative determination of substance $\mathbf{P}$ (Peninsula Laboratories), neuropeptide Y (Peninsula Laboratories), and somatostatin (Bühlmann). The antibody for substance $P$ does not show cross reactivity with neurokinin $A$ and neurokinin B. The antibody for somatostatin shows $100 \%$ cross reactivity with somatostatin-28 and somatostatin-14. The antibody for neuropeptide $\mathrm{Y}$ shows $<0.02 \%$ cross reactivity for human pancreatic polypeptide, vasoactive intestinal peptide, and peptide YY. All radioimmunoassays had an intra-assay variation $<6 \%$ and an interassay variation $<10 \%$. Sensitivity was $10 \mathrm{pg} / \mathrm{ml}$ for the substance $P$ assay, $15 \mathrm{pg} / \mathrm{ml}$ for neuropeptide $\mathrm{Y}$, and $8 \mathrm{pg} / \mathrm{ml}$ for somatostatin.

Statistical analysis was performed for untransformed and logarithmically transformed data with a one way analysis of variance (ANOVA), and the F Scheffe test for comparing between two groups. The same

Patient's characteristics, and tau protein, neuropeptide (ng/l) and glucose (g/l) concentrations in CSF of patients with dementia and controls

\begin{tabular}{lccl}
\hline & $D A T$ & $M I D$ & Controls \\
\hline MSE test & $17 \cdot 5(7 \cdot 4)$ & $19 \cdot 1(9 \cdot 1)$ & - \\
Blessed score & $12 \cdot 6(5 \cdot 3)$ & $10 \cdot 3(5 \cdot 8)$ & - \\
Hachinski score & $0 \cdot 8(1 \cdot 3)$ & $8 \cdot 2(2 \cdot 0) \dagger$ & - \\
Rosen score & $1 \cdot 7(1 \cdot 0)$ & $6 \cdot 7(3 \cdot 1) \dagger$ & - \\
Tau protein (ng/l) & $279(100)^{\star \star \star} \ddagger$ & $88(61)^{\star}$ & $26(11)$ \\
Tau protein (ng/g total protein) & $487(175)^{\star \star \star \ddagger}$ & $147(144)^{\star}$ & $65(12)$ \\
Neuropeptide Y & $70(16)$ & $83(50)$ & $67(16)$ \\
Substance P & $86(8)^{\star}$ & $95(37)$ & $122(64)$ \\
Somatostatin & $16(8)^{\star \star \ddagger}$ & $30(8)$ & $39(10)$ \\
Glucose & $0 \cdot 64(0 \cdot 14)$ & $0 \cdot 62(0 \cdot 12)$ & $0 \cdot 61(0 \cdot 12)$ \\
\hline
\end{tabular}

Values are means (SD).
${ }^{\star} \mathrm{p}<0.05 ;{ }^{\star \star} \mathrm{p}<0.01 ;{ }^{\star} \mathrm{p}<0.001 v$ controls; $\mathrm{tp}<0.001 v$ DAT; $\neq \mathrm{p}<0.001 v$ MID.

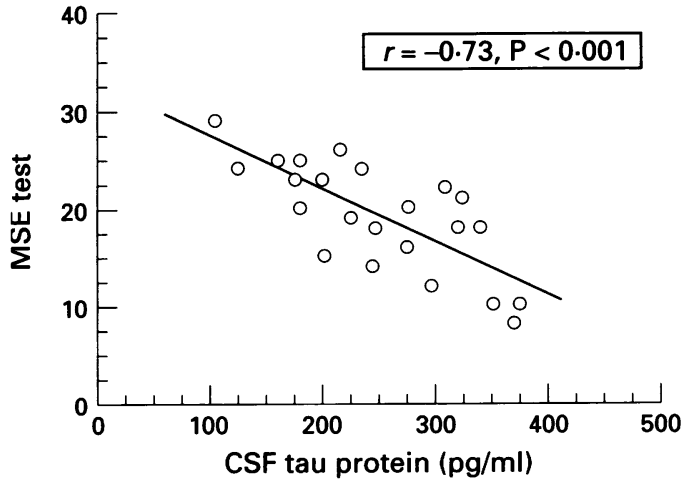

Correlation between CSF tau protein and Folstein's mental test examination (MSE) in patients with Alzheimer's disease.

significances were found for both types of data. Correlations were examined with Pearson's correlation coefficient. Significance was set at $\mathrm{P}<0.05$.

\section{Results}

All patients were mildly to moderately demented and the mean duration of illness was similar in DAT and MID groups (table). There were no significant differences in age and sex between DAT and MID groups and controls.

The table shows the tau protein concentrations in CSF in the two groups of patients and controls. These were higher in patients with DAT than those with MID ( $\mathrm{P}<0.001)$ and control $(P<0.001)$ groups, whether expressed in $\mathrm{pg} / \mathrm{ml}$ or in $\mathrm{ng} / \mathrm{g}$ total protein.

The table shows the neuropeptide concentrations in CSF in the two groups of patients and controls. Substance $P$ and somatostatin concentrations were lower in patients with DAT than in controls $(P<0.01)$, whereas neuropeptide $\mathrm{Y}$ concentration was not different between the three groups. Only somatostatin was significantly decreased in DAT compared with MID ( $\mathrm{P}<0.01)$.

In patients with DAT we found a good positive correlation between CSF tau protein and glucose concentrations $(r=0.79, \mathrm{P}<0.001)$. For cognitive function tests, there was a significant negative correlation between tau protein and the MSE test $(r=-0.73, \mathrm{P}<0.001$; (figure), but not with other neuropsychological tests (Blessed score, Rosen score). Moreover, a weak but significant correlation with the time course of DAT was found $(r=$ $0.47, \mathrm{P}<0.05$ ). We did not find significant correlations between CSF tau protein and somatostatin, substance $P$, or neuropeptide $Y$ in patients with DAT, or between tau protein concentrations and age in the three groups studied.

\section{Discussion}

Because CSF offers the richest potential source of altered proteins in neurodegenerative diseases, we were interested in quantifying tau protein concentrations in CSF from 
patients with DAT. Our results indicate that significantly increased concentrations of CSF tau protein are present in such patients. These findings agree with those of Vandermeeren et $a l,{ }^{13}$ although their values are lower than ours. In addition, a large difference between patients with DAT and MID was found. Thus there was a threefold increase in CSF tau protein concentrations in DAT compared with MID.

Increased tau concentrations have been described in brain extracts of patients with DAT, ${ }^{11} 18$ this being most evident in associative brain regions involving particularly long corticocortical projections. ${ }^{38}$ This fact may be characteristic of DAT and it could be expressed clinically by functional cognitive deficits. ${ }^{19}$ Thus we have found a significant negative correlation between the MSE test, but not with the Rosen score and Blessed dementia scale, and CSF tau protein levels in DAT patients. Because the MSE test examines patient cognitive function, the measurement of CSF tau protein might provide a correlation with the psychological symptoms and severity of disease. As in other studies, ${ }^{6} 19$ the appearance of tangles within the neocortex is a reliable marker for the presence of DAT and higher neocortical tangle densities are associated with more severe dementia.

Some studies ${ }^{319}$ that quantify tau protein in brain tissues indicate that its relation is with severity of dementia, but not with age of patients with DAT, and that its concentrations could distinguish DAT from processes occurring during normal aging. Vandermeeren et $a l^{13}$ have found increased CSF tau values in patients with DAT and controls older than 60 , but not in patients who had other diseases of the CNS. We did not find any correlation between CSF tau protein concentrations and age in patients and controls.

A recent study ${ }^{20}$ suggests that there are changes in the cytoskeleton of hippocampal neurons associated with age and they might be potentiated in Alzheimer's disease, lending to neurofibrillary tangle formation and cellular degeneration. This pattern of neuronal degeneration associated with DAT pathology can be present in mild and moderate Alzheimer's disease, and it seems to correlate with a validated instrument for staging severity of dementia. ${ }^{2122}$ This neuronal degeneration could justify the high CSF tau concentrations found in this study in patients with mild and moderate DAT.

In regard to CSF neuropeptide concentrations, we have found a reduction in substance $P$ in patients with DAT compared with controls. These data agree with those previously reported, ${ }^{91415}$ and suggest that this reduction may be due to an unequal degradation on processing of substance $P$ in patients with DAT. ${ }^{19}$ In agreement with several authors ${ }^{914}$ and our previous study, ${ }^{15}$ we have found a reduction in CSF somatostatin in patients with DAT compared with controls, and also with respect to the MID group. Immunohistochemical studies suggest that this loss may be due to a degeneration of somatostatinergic neurons ${ }^{23}$ in DAT. On the other hand, we have not found any relation between CSF neuropeptide concentrations and tau protein concentrations in DAT.

There is increasing evidence of a disrupted carbohydrate metabolism ${ }^{24}$ and a reduction in cerebral glucose use in DAT, which is comparable in extent with hypoglycaemia. ${ }^{25}$ This study reported a cerebral excess release of ammonia that may indicate an amino acid utilisation to substitute for a carbohydrate deficit in brains of patients with DAT. Decreases in brain glucose utilisation in patients with DAT can result in increased CSF glucose concentrations. It is important to point out that in our study CSF glucose concentrations correlated positively with the CSF tau protein concentrations.

In conclusion, increased concentrations of tau protein in CSF from patients with Alzheimer's disease were found. As tau protein is not found in blood or serum, its increased presence in CSF can reflect neuronal degeneration. Therefore, a simple test based on quantitative detection of tau protein in CSF fluid might be a useful marker in the diagnosis and assessment of severity in DAT. Further research is necessary to clarify the role of tau protein in patients with dementia and to establish the specificity and sensitivity of tau protein increases in DAT.

1 Khachaturian Z. Diagnose of Alzheimer's disease. Arch Neurol 1985;42:1097-105.

2 McKhann G, Drachmann D, Folstein M, Katzman R, Price D, Stadlan EM. Clinical diagnosis of Alzheimer's disease: report of the NINCDS-ADRDA Work Group under the auspices of Department of Health and Human under the auspices of Department of Health and Human 1984;34:939-44.

3 Mukaetova-Ladinska EB, Harrington CR, Roth $M$, Wischik CM. Biochemical and anatomical redistribution of tau protein in Alzheimer's disease. Am $\mathcal{f}$ Pathol 1993; of tau protein

4 Arriagada PV, Growdon JH, Hedley-White ET, Hyman BT. Neurofibrillary tangles but not senile plaques parallel duration and severity of Alzheimer's disease. Neurology 1992;42:631-9.

5 Degrell I, Hellsing K, Nagy E, Niklasson F. Amino acid concentrations in cerebrospinal fluid in presenile and senile dementia of Alzheimer type and multi-infarct dementia. Archives of Gerontology and Geriatrics 1989;9: 123-35.

6 Wilcok GK, Esiri MM. Plaques, tangles and dementia. A quantitative study. $\mathcal{f}$ Neurol Sci 1982;56:343-56.

7 Matus A. Microtubule-associated proteins: their potential role in determining neuronal morphology. Ann Rev Neurosci 1988;11:29-44.

8 Price JL, Davis PB, Morris JC, White DL. The distribution of tangles, plaques and related immunohistochemical markers in healthy aging and Alzheimer's disease. markers in healthy aging and

9 Davies P, Katzman R, Terry RD. Reduced somatostatinlike immunoreactivity in cases of Alzheimer's disease and Alzheimer senile dementia. Nature 1980;288: 279-80.

10 Ghanbari HA, Kozuk T, Miller B, Reising S. A sandwich enzyme immunoassay for detecting and measuring Alzheimer's disease-associated protein(s) in human brain tissue. F Clin Lab Anal 1990;4:189-92

11 Ghanbari HA, Miller BE, Haigler HJ, et al. Biochemical assay of Alzheimer's disease-associated protein(s) in human brain tissue. A clinical study. $¥ A M A$ 1990;263: 2907-10.

12 Mercken $M$, Vandermeeren $M$, Lübke $U$, et al. Affinity purification of human $\mathrm{T}$ proteins and the construction of a sensitive sandwich enzyme-linked immunosorben assay for

13 Vandremeeren M, Mercken M, Vanmechelen E, et al. Detection of $\tau$ protein in normal and Alzheimer's disease cetection of $\tau$ protein in normal and Alzheimer's disease linked immunosorbent assay. $\mathcal{f}$ Neurochem 1993;61: linked im.

14 Beal MF, Mazurek MF, Black PB, Martin JB. CSF somatostatin in neurological diseases. $\mathcal{f}$ Neurol Sci 1985; 71:91-104. 
15 Martinez M, Frank A, Hernanz A. Relationship of interleukin- $1 \beta$ and $\beta_{2}$-microglobulin with neuropeptides in cerebrospinal fluid of patients with dementia of Alzheimer type. $\mathcal{F}$ Neuroimmunol 1993;48:235-40.

16 Beal MF, Mazurek MF, Chattha GK, Svendsen CN, Bird ED, Martin JD. Neuropeptide immunoreactivity is reduced in cerebral cortex in Alzheimer's disease. Ann Neurol 1986;20:282-8.

17 Sakurada T, Alufuzoff I, Winblad B, Nordberg A. Substance P-like immunoreactivity, cholinergic acetyltransferase activity and cholinergic muscarinic receptors in Alzheimer's disease and multi-infarct dementia. Brain Res 1990;521:329-32.

18 Khatoon S, Grundke-Iqbal I, Iqbal K. Brain levels of microtubule-associated protein $T$ are elevated in Alzheimer's disease: a radio immuno-slot-blot assay for nanograms of the protein. $\mathcal{F}$ Neurochem 1992;59: 750-3.

19 Morris JC, McKeel DV Jr., Storandt M, et al. Very mild Alzheimer's disease: informant-based clinical, psychometric and pathologic distinction from normal aging. Neurology 1992;41:469-78.
20 Vickers JC, Riederer BM, Marugg DA, et al. Alterations in neurofilament protein immunoreactivity in human hippocampal neurons related to normal aging and Alzheimer's disease. Neuroscience 1994;62:328-33.

21 McKeel DW Jr, Ball MJ, Price JL, et al. Interlaboratory histopathologic assessment of Alzheimer neuropathology: different methodologies yield comparable diagnosogy: different methodologies yield comparable diagnos-

22 Bancher C, Braak H, Fischer P, Jellinger KA. Neurophological staging of Alzheimer lesions and intellectual status in Alzheimer's and Parkinson's disease patients. Neurosci Lett 1993;162:179-82.

23 Morrison JH, Rogers J, Scherr S, Benoit R, Bloom FE. Somatostatin immunoreactivity in neuritic plaques of Alzheimer's patients. Nature 1985;314:90-2.

24 Adolfsson R, Bucht G, Lithner F, Winblad B. Hypoglycemia in Alzheimer's disease. Acta Med Scand 1980; 208:387-8.

25 Hoyer S, Nitsch R. Cerebral excess release of neurotransmitter amino acids subsequent to reduced cerebral glucose metabolism in early onset dementia of Alzheimer type. ₹ Neural Transm 1989;75:227-32. 